\title{
ВЗАИМОСВЯЗЬ СТИЛЯ ЛИДЕРСТВА С ИНДИВИДУАЛЬНЫМИ ОСОБЕННОСТЯМИ ЛИЧНОСТИ У СОТРУДНИКОВ МЧС
}

\section{THE RELATIONSHIP OF LEADERSHIP STYLE WITH INDIVIDUAL PERSONALITY CHARACTERISTICS OF THE EMPLOYEES OF THE MINISTRY OF EMERGENCY SITUATIONS}

\section{A. Kozhevina \\ S. Dubrovina \\ E. Aydarova}

Summary: The article presents the results of studying the relationship of leadership style with individual personality characteristics of the junior and middle commanding staff of the Ministry of Emergency Situations. It is proved that there are differences in leadership style and individual characteristics, in particular, temperament, personality traits, personality orientation, the level of subjective control in the junior and middle commanding staff of the Ministry of Emergency Situations. It is shown that junior commanders have direct correlations between the democratic leadership style and the sanguine type of temperament, internality in the field of interpersonal relations, orientation to communication. For middle-level commanders, the autocratic leadership style has an inverse correlation with the level of sociability.

Keywords: leadership, individual personality traits, leadership style, emergency workers, temperament, level of subjective control.

\author{
Кожевина Анна Павловна \\ К.nсх.н., доцент, Байкальский государственный \\ университет (2. Иркутск) \\ apkozhevina@mail.ru \\ Дубровина Светлана Валериевна \\ Доцент, ФГБОУ ВО «Иркутский государственный \\ медицинский университет» Минздрава РФ \\ dubrovina.swetlana2014@yandex.ru \\ Айдарова Екатерина Дмитриевна \\ педагог-психолог, МБОУ Заларинская СОШ \\ yek.aydarowa@gmail.com
}

Аннотация: В статье представлены результаты изучения взаимосвязи стиля лидерства с индивидуальными особенностями личности у младшего и среднего начальствующего состава МЧС. Доказано, что существуют различия в стиле лидерства и индивидуальных особенностях, в частности, темпераменте, чертах личности, направленности личности, уровне субъективного контроля у младшего и среднего начальствующего состава МЧС. Показано, что у командиров младшего звена выявлены прямые корреляционные связи между демократическим стилем лидерства и сангвиническим типом темперамента, интернальностью в области межличностных отношений, направленностью на общение. У командиров среднего звена автократический стиль лидерства имеет обратную корреляционную связь с уровнем общительности.

Ключевые слова: лидерство, индивидуальные особенности личности, стиль лидерства, сотрудники МЧС, темперамент, уровень субъективного контроля.

единоначалие, которое исключает обезличивание руководства, обеспечивает организованность и наиболее полное развертывание организаторских способностей руководящего состава. Значительное место среди требований, предъявленных к руководителю, занимает умение использовать властные полномочия, возлагаемые на него служебным положением [1].

Структура МЧС иерархична и вписывается в бюрократическую систему управления, которая носит рациональный характер. Лидерство направлено на достижение цели организации, значит, оно рационально. Сотрудник, получая приказ начальника, выполняет его обдуманно, в рамках закона, следовательно, его поступок рационально обосновывается. Рациональное управление означает целесообразность или целерациональность выбора способов руководства.

Н.Б. Иглина определяет сущность лидерской модели управления организацией МЧС, которая заключается в следующем: вертикальная структура лидерства бази- 
руется на основе профессиональной и эмоциональной включённости лидера в процесс решения служебных задач и направлена на результат работы коллектива [2].

В организации деятельности органов внутренних дел ключевой фигурой является руководитель, наделенный соответствующими полномочиями. Эти полномочия позволяют ему гибко и оперативно осуществлять распорядительные, организационные и контрольные функции, направлять работу подчиненных, в том числе с применением мер дисциплинарного воздействия, представлять орган внутренних дел в иных организациях. В структуре органов внутренних дел функционируют руководители разных уровней управления.

Анализ оперативной обстановки и принятие соответствующего решения по охране общественного порядка и обеспечению безопасности граждан, планирование работы, контроль - все это важные направления деятельности начальника. Однако успех работы личного состава органа внутренних дел,в конечном счете, зависит от применяемых педагогических методов и стиля руководства [3]. Стиль руководства в контексте управления это привычная манера поведения руководителя по отношению к подчиненным, чтобы оказать на них влияние и побудить их к достижению целей организации. Степень, до которой управляющий делегирует свои полномочия, типы власти, используемые им, и забота о человеческих отношениях или о выполнении задачи -все это отражает стиль руководства [4].

Таким образом, эффективный руководитель в МЧС, выбирая стиль управления, должен иметь в виду и учитывать следующие обстоятельства: знать себя; понимать ситуацию; оценивать выбранный стиль управления адекватно ситуации и уровню подчиненных; учитывать потребности группы; учитывать нужды ситуации; учитывать нужды подчиненных [5]. Современный руководитель органа внутренних дел не может позволить себе довольствоваться раз и навсегда установленным стилем. Он должен научиться пользоваться всевозможными стилями, методами, типами влияния, наиболее подходящими для конкретной служебной ситуации, а так же использовать различные способы поддержания своего должностного и личностного авторитета в коллективе [6, 7].

Идеальной формой руководства является сбалансированное сочетание заслуженного авторитета, опыта и властных полномочий. Руководитель подразделения МЧС обязан при любых обстоятельствах умело использовать властные полномочия, контролировать свое поведение, владеть своим настроением и чувствами, быть примером для подчиненных. Таким образом, все вышесказанное позволило определить актуальность нашего исследования.
Цель исследования - выявить взаимосвязь стиля лидерства с индивидуальными особенностями личности сотрудников МЧС.

Объект исследования - лидерство как психологический феномен.

Предмет исследования - взаимосвязь стиля лидерства с индивидуальными особенностям личности у младшего и среднего начальствующего состава МЧС.

Гипотеза исследования представлена следующими допущениями:

- существуют различия в стиле лидерства и индивидуальных особенностях, в частности темпераменте, чертах личности направленности личности, уроане субъективного контроля у младшего и среднего начальствующего состава МЧС;

- существуют связь стиля лидерства с индивидуальными особенностями личности у младшего и среднего начальствующего состава МЧС.

Исследование проходило на базе МЧС г. Иркутска. В исследовании участвовали руководители разного уровня, общим количеством 40 человек. Испытуемых мы разделили на две группы: первая группа составила 20 человек, которые занимают должности младшего начальствующего состава (сержант внутренней службы, старший сержант внутренней службы, старшина внутренней службы, прапорщик внутренней службы, старший прапорщик внутренней службы); вторую группу составили 20 человек, которые занимают должности среднего начальствующего состава (младший лейтенант внутренней службы, лейтенант внутренней службы, старший лейтенант внутренней службы, капитан внутренней службы).

В исследовании использовались следующие методики: методика «Диагностика стиля лидерства» Л.В. Румянцевой, тест «Формула темперамента» А.В.Белова, многофакторный 16-факторный опросник личности Р.Б. Кеттела, методика определения направленности личности Б. Басса, в адаптации Смекала-Кучера, методика УСК, адаптирована Е.Ф. Бажиным, С.А. Голынкиной, А.М. Эткиндом.

Анализ результатов исследования стилей лидерства у младшего и среднего начальствующего состава позволил определить, что командиры среднего звена предпочитают автократический стиль лидерства (средний балл - 81,5). В группе командиров младшего звена преобладает демократический стиль лидерства (средний балл - 72,4). Таким образом, у командиров среднего звена по сравнению с командирами младшего звена, автократический стиль выражен в большей степени. А у командиров младшего звена, в сравнении с командира- 
ми среднего звена, в большей степени выражены демократический и либеральный стиль лидерства.

Диагностика индивидуальных особенностей у командиров младшего и среднего звена по тесту «Формула темперамента» А.В. Белова показала, что для командиров среднего звена наиболее характерно преобладание холерического темперамента (средний балл - 18). Также в значительной степени представлен сангвинический темперамент (средний балл - 12). Можно сказать, что преобладание двух этих темпераментов дает сочетание, которое можно назвать как холерически-сангвинический тип. Флегматический и меланхолический темперамент представлен в небольшой степени и не являются ведущими. Во второй группе выражен в значительной степени сангвинический и флегматический тип темперамента (средний балл - 13 и 12 соответственно). У таких руководителей активность сочетается с медлительностью. Происходят быстрые фазы изменения настроения от высокой до низкой психической активности. Холерический и меланхолический темпераменты в данной группе представлены слабо.

Таким образом, в группе командиров среднего звена преобладает холерический и сангвинический темпераменты, а у командиров младшего звена - флегматический и сангвинический.

Показатели теста Р.Б. Кеттелла у младшего и среднего начальствующего состава позволили определить, что командиры среднего звена и младшего звена в одинаковой степени проявляют открытость (фактор А - средний балл равен и в первой, и во второй группе - 6,5 баллов), развитое мышление (фактор B; соответственно 2,8 балла и 2,6 балла), развитое воображение (фактор М; соответственно 5,4 балла и 5,8 балла, дипломатичность (фактор N; соответственно 6,4 балла и 6,8 балла), высокий самоконтроль (фактор Q3; соответственно 7,1 балла и 7,0 балла).

Также командиры среднего звена, в сравнении с командирами младшего звена, в большей степени проявляют эмоциональную устойчивость (фактор C - 4,9 балла и 3,5 балла соответственно), нормативность поведения (фактор G - 6,9 балла и 5,3 балла соответственно), смелость (фактор Н - 5,3 балла и 4,0 балла соответственно), твердость (фактор I - 4,8 балла и 4,1 балла соответственно), радикализм (фактор Q1 - 4,9 балла и 3,5 балла соответственно).

В свою очередь, командиры младшего звена, по сравнению с руководителями среднего командного звена, в большей степени проявляют независимость (фактор Е 6,9 балла и 5,7 балла соответственно), экспрессивность (фактор F - 4,8 балла и 4,3 балла соответственно), подозрительность (фактор $L-6,8$ балла и 5,6 балла соответ- ственно), склоннность к чувству вины (фактор О - 7,5 балла и 5,7 балла соответственно), самостоятельность (фактор Q2 - 6,8 балла и 4,4 балла соответственно), внутреннюю напряженность (фактор Q4 - 5,0 балла и 4,4 балла соответственно).

Показатели, полученные по тесту определения направленности личности (Б. Басса), в адаптации СмекалаКучера указывают на то, что командиры среднего звена и младшего звена в одинаковой степени проявляют направленность на себя (соответственно 8,3 балла и 8,5 балла). Это говорит о том, что командиры обеих групп характеризуются преобладанием мотивов собственного благополучия. Направленность на общение преобладает в группе командиров младшего звена (соответственно 7,5 балла и 8,1 балл). Командиры среднего звена по сравнению с командирами младшего звена в большей степени проявляют направленность на деятельность (соответственно 11,3 балла и 9 балла). Если говорить о доминирующей направленности личности, то для командиров среднего звена характерна направленность на деятельность, а руководителям младшего командного звена также свойственна направленность на деятельность, но она имеет более низкие показатели.

Полученные результаты по методике УСК (уровень субъективного контроля) адаптированой Е.Ф. Бажиным, С.А. Голынкиной, А.М. Эткиндом указывают на то, что командиры среднего командного звена и младшего звена в одинаковой степени проявляют интернальность в области неудач (соответственно 4,1 балла и 4,2 балла), интернальность в области семейных отношений (соответственно 5,3 балла и 4,8 балла), интернальность в области производственных отношений (соответственно 3,5 балла и 3,3 балла). Командиры среднего звена по сравнению с командирами младшего звена в большей степени проявляют общую интернальность (соответственно 4,5 балла и 3,1 балла), интернальность в области достижений (соответственно 5,8балла и 3,9 балла), интернальность в области межличностных отношений (соответственно 7,5 балла и 5,9 балла). Командиры младшего звена по сравнению с командирами среднего звена, в большей степени проявляют интернальность в отношении к здоровью и болезни (соответственно 7,8 балла и 6,2 балла).

Применение статистического критерия U - критерия Манна-Уитни позволило доказать, что командирам свойственны определенные стили лидерства. Так, у командиров среднего звена преобладает автократический стиль лидерства $(U=535,2, p=0,000)$, а у командиров младшего звена - демократический стиль лидерства $(U=453,7$, $\mathrm{p}=0,002)$.

Достоверные развличия получены в выраженности темперамента у командиров $(U=434,02, p=0,000)$. Так, командиров среднего звена в большей степени выра- 
жен холерический темперамент.

Также выявлены достоверные различия по фактору C - «эмоциональная устойчивость -неустойчивость» $(U=533,6, p=0,013)$. Следовательно, командиры среднего звена в большей степени проявляют эмоциональную стабильность спокойствие, уверенность постоянство в чувствах, отсутствие страха перед сложными ситуациями.

Достоверные различия по фактору G — «подверженность чувствам - высокая нормативность поведения» (U $=745,9, p=0,000$ ) указывает на то, что среднего командного звена по сравнению с руководителями младшего командного звена, в большей степени проявляют сознательность, выдержанность, решительность, обязательность, ответственность, готовность к действию, основательность, упорство в достижении цели, стремление к социальной нормативности своих поступков.

Полученные достоверные различия по Н - фактору «робость - смелость» $(U=666,0 \mathrm{p}=0,001)$ означают, что командиры среднего звена в большей степени проявляют смелость, легкость в знакомствах с людьми, реактивность, бодрость, чем руководители младшего командного звена. Получены значимые различия по О - фактору «уверенность в себе - тревожность» $(U=576,0, p=0,031)$.

Достоверные различия по фактору Q 1 - «консерватизм - радикализм» $(U=543,1, p=0,012)$ указывают на преобладание у командиров среднего звена радикализма. Достоверные различия по фактору Q2 - «конформизм - нонкомформизм» $(U=647,2, p=0,001)$, указывают на то, что у командиров среднего звена наиболее представлена самостоятельность, ориентация на собственное мнение, независимость во взглядах, стремление к самостоятельным решениям и действиям. Выявлены достоверные различия в показателях общей интернальности ( $U=376,5, p=0,012)$. Это свидетельствует о том, что у командиров среднего звена по сравнению с командирами младшего звена, в большей степени проявляют общую интернальность.

Также выявлены значимые различия в интернальности в области достижений $(U=503,5, p=0,002)$. Это указывает на то, что командирам среднего звена в большей степени проявляют интернальность в области достижений, которая заключается в высоком уровне субъективного контроля над эмоционально положительными событиями и ситуациями.

Получены достоверные различия в показателях направленности на деятельность ( $U=423,7, p=0,040)$. Это указывает на то, что у командиров среднего звена большей степени проявляется направленность личности на деятельность, которая выражена в заинтересованности в решении деловых проблем, выполнении работы как можно лучше, ориентации на деловое сотрудничество, способности отстаивать в интересах дела собственное мнение.

Корреляционный анализ Спирмена позволил определить, что авторитарный стиль лидерства имеет обратную корреляционную связь с фактором A «замкнутость общительность» $(r=-0,47)$ и фактором O «уверенность В себе - тревожность $(r=-0,57)$. Прямая корреляционная связь выявлена между автократическим стилем руководства и фактором Q3 - «низкий самоконтроль - высокий самоконтроль» $(r=0,618)$. То есть, чем выше самоконтроль командиров, тем более руководитель высшего звена направлен на автократический стиль лидерства. Прямые корреляционные связи выявлены между автократическим стилем лидерства и холерическим темпераментом $(r=0,355)$; интернальностью в области достижений $(r=0,289)$, направленностью на деятельность $(r=$ 0,373).

Демократический стиль лидерства у командиров младшего звена прямо коррелирует с фактором А «замкнутость - общительность» $(r=0,540)$. Это говорит о том, что чем выше общительность командиров младшего звена, тем ярче выражен демократический стиль лидерства. Также прямая связь выявлена с фактором Q4 «расслабленность - напряженность» $(r=0,567)$. Обратная связь выявлена с фактором О - «уверенность-тревожность» $(r=0,586)$. Так, чем ниже тревожность у командиров младшего звена, тем в большей степени выражен демократический стиль лидерства. Выявлены прямые корреляционные связи между демократическим стилем лидерства и сангвиническим типом темперамента $(r=0$, 322), интернальностью в области межличностных отношений $(r=0,544)$, направленностью на общение $(r=0$, 455).

Таким образом, демократический стиль лидерства напрямую связан с уверенностью командиров младшего звена в том, что они способны неформальные отношения с другими людьми, вызывать к себе уважение и симпатию, стремиться при любых условиях поддерживать отношения с людьми, ориентироваться на совместную деятельность, ориентироваться на социальное одобрение и потребность в привязанности и эмоциональных отношениях с людьми.

Таким образом, нами доказана гипотеза, представленная двумя допущениями о том, что существуют различия в стиле лидерства и индивидуальных особенностях, в частности, темпераменте, чертах личности, направленности личности, уровне субъективного контроля у младшего и среднего начальствующего состава МЧС; а также, что существует связь стиля лидерства с индивидуальными особенностями личности у младшего и среднего начальствующего состава. 


\section{ЛИТЕРАТУРА}

1. Никулина Т.И. Мотивация достижения в выборе стратегии поведения в организационном конфликте у сотрудников пригородной железной дороги / Т.И. Никулина, Ю.В. Чепурко. - D0I: 10.17150/2411-6262.2021.12(1).21 // Baikal Research Journal. - 2021. - Т. 12, №1. - С. $21-21$

2. Устинова Л.Г. Управленческая культура руководителя ОВД в контексте современных стилей и методов руководства // Научно-методический электронный журнал «Концепт». 2014. Т. 20. С. 2006 - 2010.

3. Демидова Е.В. Модель взаимосвязи мотивационной системы личности и организационной культуры / Е.В. Демидова. - DOI: 10.17150/24116262.2021.12(2).25 // Baikal Research Journal. - 2021. - T. 12, №2. - C. 25-25

4. Воронцова Е.Г. Взаимосвязь представлений о самоэффективности с мотивацией достижения успеха у юношей и девушек, обучающихся на психологическом и юридическом направлениях обучения в вузе / Е.Г. Воронцова. DOI: 10.17150/2411-6262.2019.10(1).3 // Baikal Research Journal. - 2019. - T. 10, №1. - C. 3-3

5. Фонталова Н.С. Взаимосвязь потребности во властвовании и системы жизненных смыслов у современной молодежи / Н.С. Фонталова, Ю.0. Рюмкина. DOI: 10.17150/2411-6262.2021.12(3).23 // Baikal Research Journal. - 2021. - T. 12, №3. - С. 23-23

6. Иглина Н.Б. Лидер как субъект процесса социального управления в правоохранительных органах / автореферат по ВАК РФ 09.00.11, на соискание степени кандидата философских наук. 25 c.

7. Лимонцева Г.В. Взаимосвязь ценности патриотизма с личностными характеристиками студенческой молодежи / Г.B. Лимонцева. - D0I: 10.17150/24116262.2017.8(3).27 // Baikal Research Journal. - 2017. - T. 8, №3. - C. 27-27
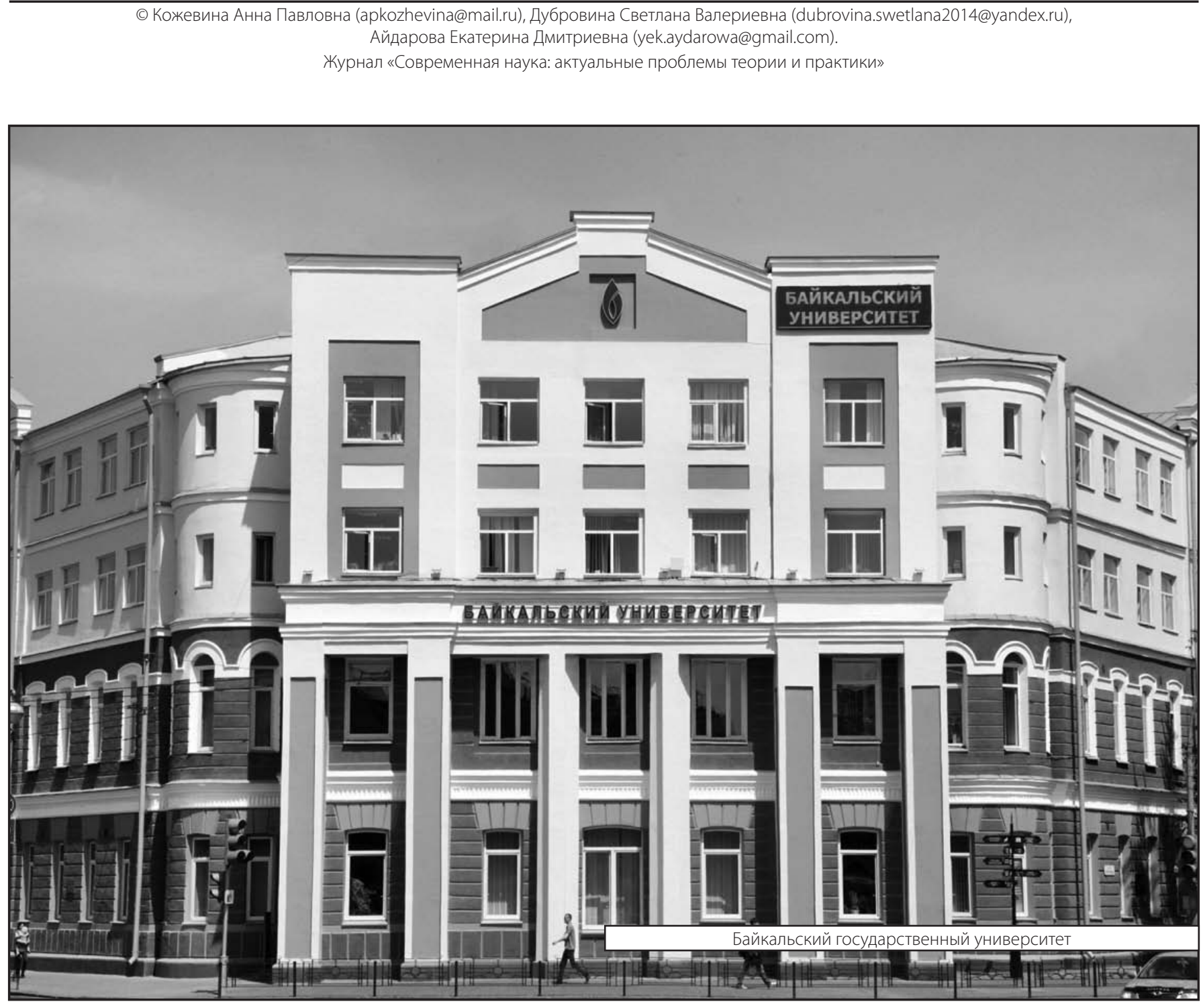